\title{
ANALISA KEAUSAN SPROKET PADA SEPEDA MOTOR SPORT 4 LANGKAH 150 CC
}

\author{
AHMAD ISKANDAR ${ }^{1}$, MOCHAMAD JOHANSYAH ${ }^{2}$, M FAJAR SIDDIQ ${ }^{3}$ \\ Program Studi Teknik Mesin, Fakultas Teknik, Universitas Muhammadiyah Tangerang \\ Jl. Perintis Kemerdekaan I/33 Cikokol-Tangerang \\ E-Mail :Iskandar.umt@yahool.com
}

\begin{abstract}
ABSTRAK
Sproket rantai rol pada sepeda motor merupakan komponen yang sangat penting, komponen ini berfungsi untuk mentransmisikan daya dari mesin penggerak ke roda belakang. Dalam pengoperasiannya komponen sproket selalu bergesekan dengan rantai dari sepeda motor, dari gesekan tersebut yang akan menyebabkan keausan dan berkurangnya umur pakai. Jenis keausan yang terjadi pada komponen sproket yaitu keausan adhesi dan abrasi, sedangkan untuk umur pakai sendiri dari komponen sproket yang diteliti telah mengalami pemakaian selama 420 hari atau 30.738 .960 siklus. Untuk umur pakai sproket sampai kondisi harus diganti, pemakaian selama 4,1 tahun atau 105,742,022,4 siklus. Komponen sproket sendiri sebelumnya telah dilakukan proses pengerasan permukaan, dengan metoda induksi. Dari hasil pengujian kekerasan dapat dilihat penurunan harga kekerasan dari permukaan ke bagian dalam. Strktur mikro yang terbentuk pada daerah permukaan yang dikeraskan terbentuk fasa martensit dan ferrite, sedangkan untuk daerah yang potongan melintang memiliki martensit austenit, perit (hitam) dan pearlite. Komponen sproket termasuk ke dalam baja karbon medium, sesuai dengan AISI 1040.
\end{abstract}

Kata Kunci : Keausan; Umur Sproket; Kompnen Sproket.

\begin{abstract}
Roller chain sprocket on a motorcycle is a very important component, this component functions to transmit power from the drive engine to the rear wheel. In its operation the sprocket component always rubs against the chain of the motorcycle, from friction that will cause wear and reduced life. The type of wear that occurs in the sprocket component is the wear of adhesion and abrasion, while for the self-use age of the sprocket component under study has been used for 420 days or 30,738,960 cycles. For age use sprocket until conditions must be replaced, usage for 4.1 years or 105,742,022.4 cycles. The sprocket component itself has previously been surface hardened, with an induction method. From the results of hardness testing can be seen a decrease in the price of violence from the surface to the inside. The microstructure that formed on the hardened surface area formed martensite and ferrite phases, while for the cross-sectional areas the martensite austenite, perit (black) and
\end{abstract}

Keywords: Wear; Sprocket Age; Sprocket Components.

\section{PENDAHULUAN}

Sepeda motor merupakan kendaraan yang cocok digunakan untuk menjangkau berbagai daerah dan tempat terpencil dengan pertimbangan ongkos yang murah. Harga satu unit kendaraan bermotor yang terjangkau oleh sebagian besar masyarakat, menyebabkan kendaraan bermotor paling banyak digunakan dan dijumpai di jalan-jalan raya. Oleh karena itu, keamanan dan keselamatan merupakan prioritas utama saat kendaraan ini bergerak

Sepeda motor dituntut mampu bergerak cepat dengan tidak menyebabkan terlepasnya rantai dari gearnya (sprocket). Apabila rantai terlepas dari gear pada kondisi di mana jalanan ramai, maka hal ini akan sangat berbahaya bagi keamanan dan keselamatan pengendara. Demikian pula, pengendara kendaraan bermotor lainnya.
Dalam pengoperasiannya, komponen sproket selalu bergesekan dengan rantai dari sepeda motor. Gesekan dari kedua komponen tersebut mengakibatkan terjadinya getaran dan tumbukan yang terus menerus sehingga komponen sproket tersebut akan mengalami keausan

Dengan demikian, terjadinya keausan pada komponen sproket akan berpengaruh atau akan mengurangi umur pakai dari komponen sproket. Mengingat vitalnya fungsional sproket pada sepeda motor maka akan dilakukan penelitian terhadap komponen sproket tersebut. 


\section{METODOLOGI PENELITIAN}

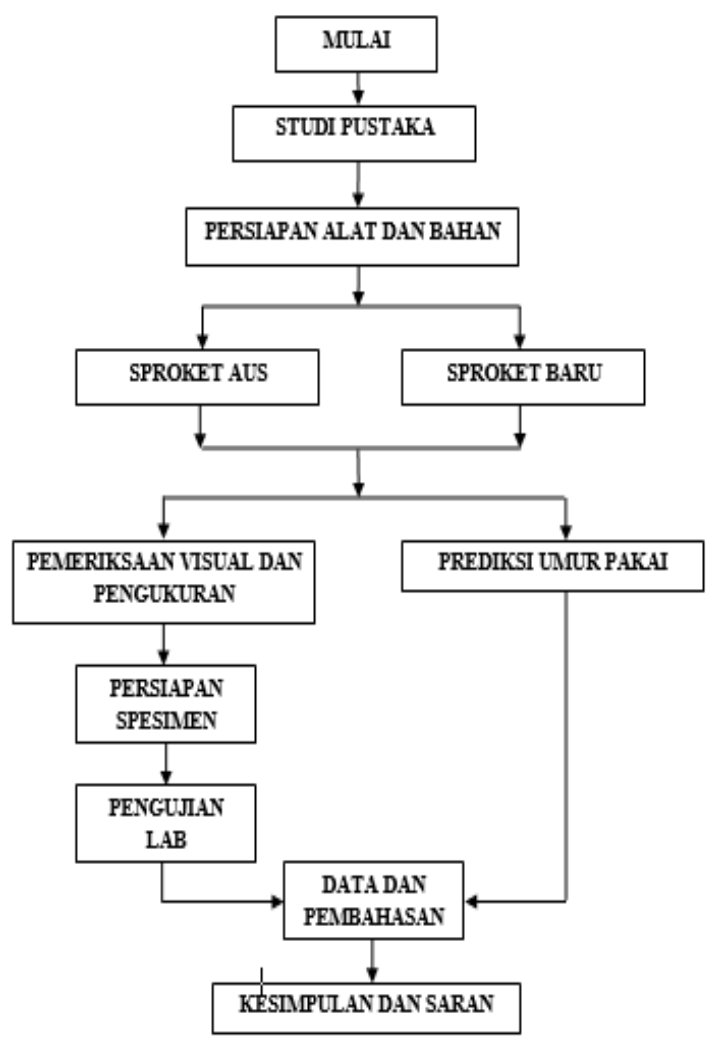

Gambar 1. Diagram Alir Penelitian

Honda Verza adalah motor keluaran dari Honda, dimana spesifikasi bisa dilihat di tabel dibawah ini

Tabel 1. Spesifikasi Sepeda Motor Honda Verza 150

\begin{tabular}{|c|c|}
\hline Tipe Mesin & 4 Langkah, SOHC, Satu Silinder \\
\hline Sistem Suplai Bahan Bakar & PGM-FI \\
\hline Diamter X Langkah & $57,3 \times 57,8$ \\
\hline Tipe Transmisi & 5 Tingkat Kecepatan \\
\hline Rasio Kompresi & $9,5: 1$ \\
\hline Daya maksimum & $9,59 \mathrm{~kW}(13,04 \mathrm{PS}) / 8.500 \mathrm{rpm}$ \\
\hline Torsi Maksimum & $12,73 \mathrm{Nm}(1,30 \mathrm{Kgf.m}) / 6.000 \mathrm{rpm}$ \\
\hline Tipe Stater & $\begin{array}{l}\text { Pedal dan Elektrik } \\
\end{array}$ \\
\hline Tipe Kopling & Manual, Multiplate, Wet Clutch \\
\hline Sitem Pendingin Mesin & Pendingin Udara \\
\hline Pola Perpindahan Gigi & $1-\mathrm{N}-2-3-4-5$ \\
\hline Tipe Rangka & Diamond Stell \\
\hline Tipe Suspensi Depan & Teleskopik \\
\hline Tipe Suspensi Belakang & Adjustable Dual Rear Suspension \\
\hline Ukuran Ban Depan & $80 / 100-17 \mathrm{M} / \mathrm{C} 46 \mathrm{P}$ \\
\hline Ukuran Ban Belakang & $100 / 90-17 \mathrm{M} / \mathrm{C} 55 \mathrm{P}$ \\
\hline Rem Depan & Cakram Hidrolik, Piston Ganda \\
\hline Rem Belakang & Tromol \\
\hline Panjang x Lebar $\mathrm{x}$ Tinggi & $2.056 \times 742 \times 1054 \mathrm{~mm}$ \\
\hline Tinggi Tempat Duduk & $773 \mathrm{~mm}$ \\
\hline Jarak Sumbu Roda & $1.318 \mathrm{~mm}$ \\
\hline Jarak Terendah Ketanah & $156 \mathrm{~mm}$ \\
\hline Curb Weight & $129 \mathrm{~kg}$ (Cast Whell) dan $128 \mathrm{~kg}$ (Spoke Whell) \\
\hline Kapasitas Tangki Bahan Bakar & 12,2 Liter \\
\hline Kapasitas Minyak Pelumas & 1,0 Liter \\
\hline Tipe Baterai atau Aki & MF Wet $12 \mathrm{~V} 3.5 \mathrm{Ah}$ \\
\hline Sistem Pengapian & Full Transisterized \\
\hline Tipe Busi & NGK CPR9EA-9 \\
\hline
\end{tabular}

Sproket Honda Verza Terbuat dari material berkualitas tinggi dan tingkat pengerjaan yang presisi yang disesuaikan dengan spesifikasi dan ukuran rantai roda Honda, guna mendapatkan usia pemakaian yang optimum. Sproket honda verza memiliki 41 roda gigi. Gambar 2.10 menunjukan Chain Set dari Honda Verza

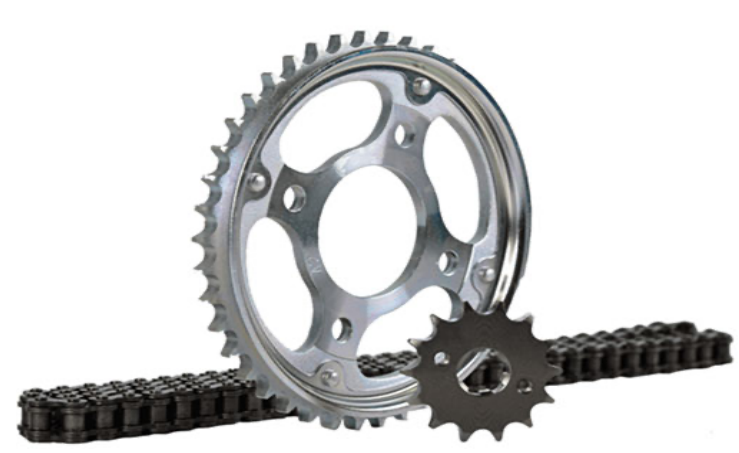

Gambar 2. Sproket Honda Verza

Selanjutnya dilakukan pengujian laboratorium dengan yang terdiri dari pengujian komposisi, kekerasan dan metalografi. Tujuan dari pengujian komposisi ini adalah mengetahui komposisi dasar dari suatu material. Pengujian ini dilakukan di B2TKS Puspitek dengan menggunakan alat Spektralanalyse PMI-Master-Pro. Adapun Prosedur yang dilakukan pada pengujian komposisi adalah sebagai berikut:

a) Dipersiapkan spesimen untuk uji komposisi

b) Spesimen dilakukan proses polishing.

c) Kemudian spesimen dipolish lagi dengan menggunakan autosol hingga terlihat seperti cermin.

d) Kemudian dilakukan pengujian komposisi dengan menggunakan alat Spectometer.

e) Alat ini bekerja menggunakan prinsip pantulan cahaya ke spesimen uji.

f) Pantulan cahaya dari unsur akan langsung di input kedalam komputer dan akan dihasilkan data hasil komposisi.

Pengujian kekerasan bertujuan untuk menentukan kekerasan suatu material. Pengujian ini dilakukan di beberapa titik. Pengujian kekerasan terhadap spesimen material sproket menggunakan metode vicker dan dilakukan di Laboratorium B2TKS Puspitek. Adapun prosedur yang dilakukan pada pengujian kekerasan adalah sebagai berikut:

a) Dipersiapkan spesimen uji kekerasan

b) Spesimen dilakukan proses polishing

c) Kemudian dilakukan pengujian kekerasan

d) Pengujian ini dilakukan dibeberapa titik 
e) Pengujian kekerasan terhadap spesimen sproket coran menggunakan metode vicker.

Pengujian metalografi dilakukan untuk melihat mikrostruktur yang ada dipermukaan spesimen. Pengujian ini dilakukan di Laboratorium B2TKS Puspitek. Adapun prosedur yang dilakukan untuk pengujian metalografi adalah sebagai berikut:

a) Dipersiapkan spesimen untuk metalografi.

b) Spesimen dilakukan polishing.

c) Kemudian spesimen dipolish lagi dengan menggunakan autosol hingga terlihat seperti cermin.

d) Spesimen di oleskan etsa.

e) Dilihat lebar jejak keausan dan mikrostruktur yang ada dipermukaan specimen.

\section{HASIL DAN PEMBAHASAN}

\subsection{Hasil Pengamatan Data Lapangan}

Adapun data lapangan dari sproket yang diperoleh sebagai berikut:

Tabel 2. Pengamatan Data Lapangan Sproket

\begin{tabular}{|c|c|c|}
\hline Data Awal & Sproket Aus (A) & Sproket Baru (B) \\
\hline Nama komponen & Sproket & Sproket \\
\hline Pemakaian Terakir $(\mathrm{km})$ & $25843 \mathrm{~km}$ & - \\
\hline Fungsi Komponen & \multicolumn{2}{|c|}{ Mentramisikan daya darimesin penggerak ke roda belakang } \\
\hline
\end{tabular}

Tabel 3. Data Pengukuran Sproke

\begin{tabular}{|c|c|c|}
\hline Posisi Pengukuran & Sproket Aus & Sproket Baru \\
\hline Tebal Sproket & 8,7 & 8,8 \\
\hline Diameter Luar & $161 \mathrm{~mm}$ & $167 \mathrm{~mm}$ \\
\hline Diameter Dalam & $147 \mathrm{~mm}$ & $147 \mathrm{~mm}$ \\
\hline Berat Sproket & 468 gram & 489 gram \\
\hline
\end{tabular}

\subsection{Uji Komposisi Kimia}

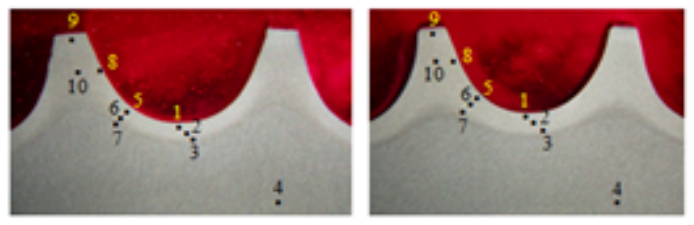

Tabel 4. Uji Komposisi Kimia

\begin{tabular}{|c|c|c|c|}
\hline \multirow{2}{*}{ No. } & \multirow{2}{*}{ Unsur } & \multicolumn{2}{|c|}{ Kandungan unsur (\% berath } \\
\cline { 3 - 4 } & & Sprocket ex-pakai & Sprocket Baru \\
\hline 1 & Fe & 98.8 & 98.8 \\
\hline 2 & $\mathrm{C}$ & 0.215 & 0.224 \\
\hline 3 & Si & 0.0261 & $<0.0050$ \\
\hline 4 & $\mathrm{Mn}$ & 0.0281 & 0.824 \\
\hline 5 & $\mathrm{Cr}$ & 0.0046 & 0.0110 \\
\hline 6 & $\mathrm{Ni}$ & $<0.0050$ & $<0.0050$ \\
\hline 7 & $\mathrm{Mo}$ & 0.0205 & 0.0103 \\
\hline 8 & $\mathrm{Cu}$ & 0.0097 & 0.0073 \\
\hline 9 & $\mathrm{~A}$ & 0.0295 & 0.0205 \\
\hline 10 & $\mathrm{~V}$ & $<0.0020$ & $<0.0020$ \\
\hline 11 & $\mathrm{~W}$ & $<0.0250$ & $<0.0250$ \\
\hline 12 & $\mathrm{~T}$ & 0.0170 & 0.0161 \\
\hline 13 & $\mathrm{Nb}$ & $<0.0030$ & $<0.0030$ \\
\hline 14 & $\mathrm{Fb}$ & 0.0189 & 0.0213 \\
\hline 15 & $\mathrm{~S}$ & 0.0021 & 0.0021 \\
\hline 16 & $\mathrm{P}$ & 0.0193 & 0.0175 \\
\hline 17 & $\mathrm{Co}$ & $<0.0020$ & $<0.0020$ \\
\hline 18 & $\mathrm{Sn}$ & $<0.0019$ & $<0.0019$ \\
\hline
\end{tabular}

\subsection{Uji Kekerasan}

Tabel 5. Uji kekerasan

\begin{tabular}{|c|c|c|}
\hline \multirow{2}{*}{ No. } & \multicolumn{2}{|c|}{ Nilai Kelzerasan, HV } \\
\cline { 2 - 3 } & Sprocket Banu & Sprocket Ex-pakai \\
\hline 1 & 472 & 472 \\
\hline 2 & 523 & 460 \\
\hline 3 & 523 & 466 \\
\hline 4 & 158 & 158 \\
\hline 5 & 349 & 472 \\
\hline 6 & 332 & 472 \\
\hline 7 & 321 & 478 \\
\hline 8 & 306 & 485 \\
\hline 9 & 371 & 412 \\
\hline 10 & 299 & 500 \\
\hline Rata Rata & 365.4 & 437.5 \\
\hline
\end{tabular}

\subsection{Uji Metalografi Sproket Aus dan baru}

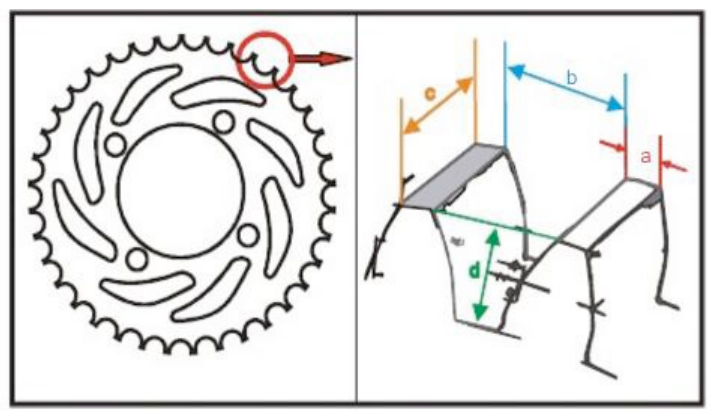



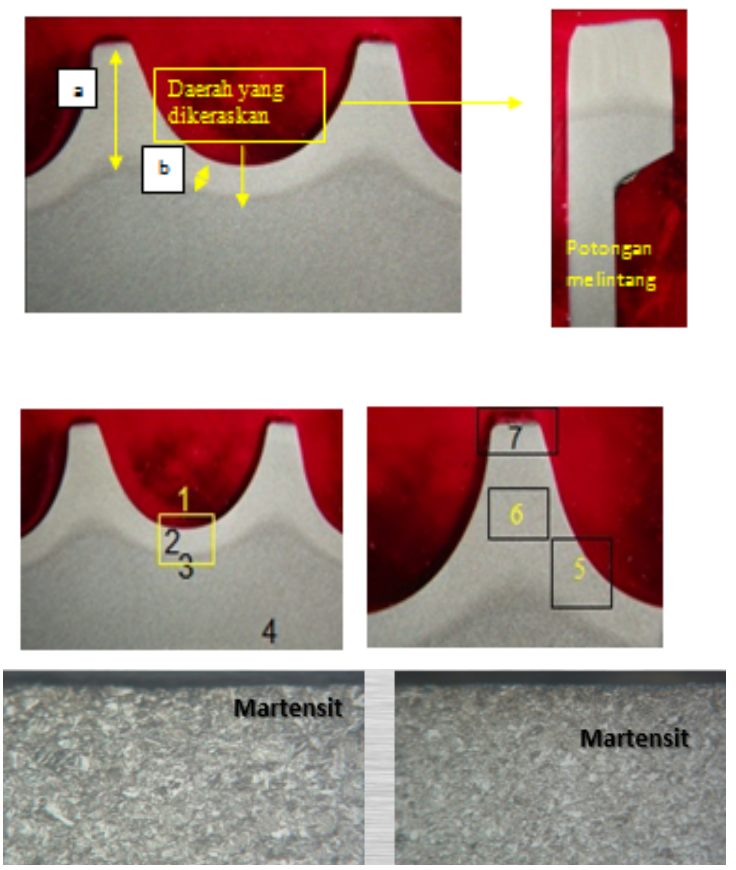

Posisi 1 Aus (kiri) dan Baru (Kanan)

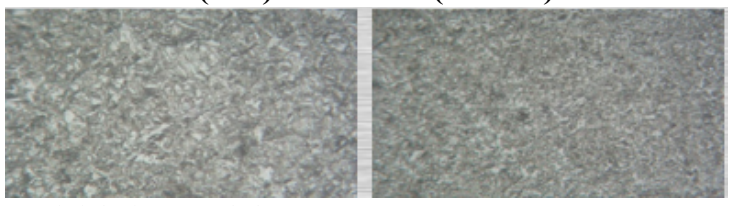

Posisi 2 Aus (kiri) dan Baru (Kanan)

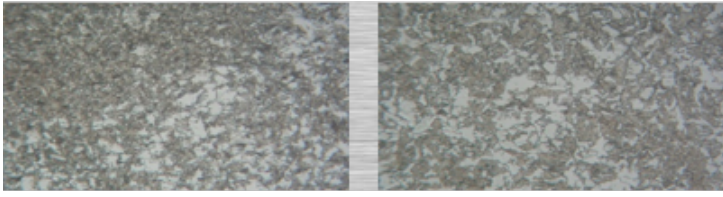

Posisi 3 Aus (kiri) dan Baru (Kanan)

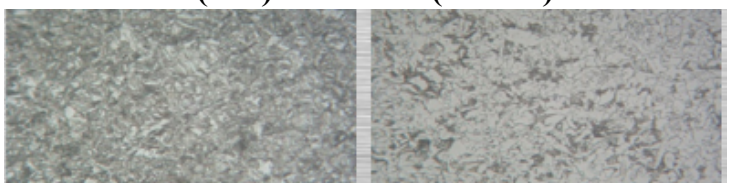

Posisi 4 Aus (kiri) dan Baru (Kanan)

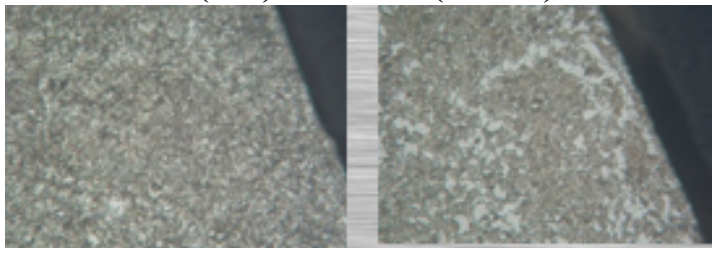

\section{Posisi 5 Aus (kiri) dan Baru (Kanan)}

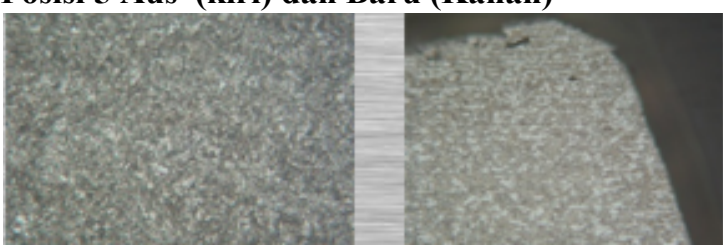

Posisi 6 Aus (kiri) dan Baru (Kanan)

Gambar 3. Hasil Uji Metalografi Sproket

\subsection{Umur Pakai Sproket yang diteliti}

Berdasarkan data lapangan

$\begin{array}{ll}\text { Berat sproket baru } & =469 \text { gram } \\ \text { Berat sproket aus } & =464 \text { gram }\end{array}$

Selisih berat kedua sproket 5 gram

Pembelian motor = Juni 2017

Penelitian terhadap sproket $=$ Agustus 2018

Jadi motor telah digunakan selama 1 tahun, 2 bulan $=14$ bulan $=420$ hari

Dalam waktu 420 hari mengalami kehilangan berat 5 gram dengan asumsi pemakaian satu hari 2 jam atau 120 menit.

Jadi 120 x n (Rpm) v=70 km/jam

$=1.166 .666,66 \mathrm{~mm} / \mathrm{menit}$

(n) $: \mathrm{v}=\pi . \mathrm{D}$ (Roda). $\mathrm{n}$

$\mathrm{D}($ roda $)=610 \mathrm{~mm}$

$$
\begin{aligned}
\mathrm{n} & =\frac{v}{\pi \cdot D} \\
& =\frac{1.166 .666,66}{3.14 .610}=\frac{1.166 .666,66}{1915.4} \\
& =609,09 \mathrm{Rpm}
\end{aligned}
$$

Jadi untu hari 120 x $609,09=73.188$ Siklus/hari

Untuk 420 har

$73.188 \times 420=30.738 .960$ siklus

\subsection{Umur pakai sproket sampai diganti}

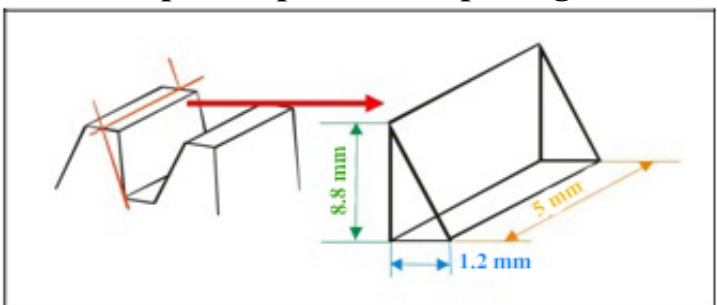

Gambar 4. Sproket

L segitiga $\quad=1 / 2$ a.t

$\mathrm{V}$ segitiga $\quad=\mathrm{L}$ alas $\mathrm{x}$ tinggi

$=5,3 \times 5=26,5 \mathrm{~mm} 3$

$\mathrm{V}$ tot 1 gigi $=26,5 \times 2=53 \mathrm{~mm}^{3}$

$\mathrm{V}$ tot Sproket $\quad=53 \times 41=2173 \mathrm{~mm}^{3}$

$$
=2,2 \mathrm{~cm}^{3}
$$$$
\mathrm{m}=\mathrm{V} \times \rho
$$$$
=2,2 \times 7,8=17,2 \text { gram }
$$

Perbandingan hari

$$
\begin{aligned}
& 420 \text { Hari }=5 \text { gram } \\
& \mathrm{x} \text { hari }=17,2 \text { gram }
\end{aligned}
$$

1444,8 hari $=48,16$ bulan

48.16 bulan $=4$ tahun

Untuk 1444,8 hari :

$73.188 \times 1444,8=105,742,022,4$ Siklus 


\section{KESIMPULAN}

Dari hasil pengujian metalografi karakteristik sproket baru dan aus berupa martensit dan ferrite dengan perbedaan pada lembah roda gigi aus di potongan melintang terlihat titik keuasan tersebut.

1. Dari hasil pengujian komposisi kimia komponen sproket termasuk kedalam jenis baja karbon medium, seri AISI 1040 dengan persen karbon 0,225 \%.

2. Dari hasil penelitian diketahui bahwa besarnya keausan umur sproket yang terjadi selama 420 hari yaitu 30.738 .960 siklus

3. Dari hasil penlitian umur sproket sampai harus diganti yaitu 105,742,022,4 siklus atau 1444,8 hari atau 4 tahun.

4. Keausan pada komponen sproket terjadi hanya pada gigi sproket bagian lembah gigi.

5. Faktor penyebab terjadinya keausan yaitu kurangnya pelumasan terhadap komponen sproket, juga partikel abrasif dari kondisi operasi.

Dari hasil penelitian yang dilakukan, penulis menyarankan bahwa perlu dilakukan perawatan (maintenance) dalam hal ini pelumasan terhadap komponen sproket secara berkala. Untuk menghindari partikel abrasif, penulis menyarankan pada sproket rantai rol digunakan pelindung/penutup rantai.

\section{DAFTAR PUSTAKA}

Arismunandar, W (2002)), Penggerak Mula Motor Bakar Torak, Bandung : Penerbit ITB.

Astra

Honda Motor. (2013) Modul Training Product Knowlegde "Honda Verza". Jakarta.

ASM International. Handbook Committee (2000), "ASM Handbook: Mechanical testing and evaluation" Volume 8. ASM International, Universitas Of California USA.

Ernest Rabinowicz (1995), "Friction and Wear of Materials" Wiley USA.

Keith Mobley, Lindley Higgins, Darrin Wikoff (2008), "Maintenance Engineering Handbook", McGraw Hill Book Company, New York.

Sularso (1987), "Dasar Perencanaan Dan Pemilihan Elemen Mesin" PT Pradnya Paramita, Jakarta.

http://web.ipb.ac.id/ tepfteta/elearning/media/Bahan \%20Ajar\%20Motor\%20dan\%20Tenaga\%20 Pertanian/sistem\%20transmisi\%20tenaga1.html ( Rabu, 05 September 2018). https://ftkceria.wordpress.com/2012/04/28/ujikeausan-wear/ (Sabtu, 08 September 2018). http://eprints.undip.ac.id/41435/4/4_REVISI_KE_2 BAB_II_YANTO.pdf( Selasa, 11 September 2018) 